ASME Turbo Expo 2019: Turbomachinery Technical Conference and Exposition

\title{
ANALYSIS OF THE HONEYWELL UNCERTIFIED RESEARCH ENGINE (HURE) WITH ICE CRYSTAL CLOUD INGESTION AT SIMULATED ALTITUDES
}

GT2019-90002

June 17 - 21, 2019, Phoenix, Arizona, USA

Joseph P. Veres, Philip C.E. Jorgenson, Samaun Nili, Shashwath R. Bommireddy, Kenneth L. Suder

National Aeronautics and Space Administration, Glenn Research Center Cleveland, Ohio, USA 


\section{Outline}

Background

Computational Process

Engine and Compressor Flow Analysis

- Fan Stator Region

- Splitter-Lip-Shroud Region

- Variable Inlet Guide Vane

Uncertainty

Conclusions 


\section{Background}

- Ice crystals ingested into turbofan engines during the operation of commercial aircraft at high altitudes can result in ice accretion in the compression system.

- As ice crystals are ingested into the fan, a portion of the ice crystals melt due to the rising static temperature of the air, ice-water mixture then impacts and cools the surfaces through evaporation and ultimately ice accretes on the compressor components.

- The accreted ice can cause one or more of the following modes of failure: uncommanded loss of thrust control, compressor surge or stall, ice shedding which can result in structural damage to the compressor blades, and possible combustor flameout.

- To improve understanding of the causes of ice accretion within an engine, full engine testing with ice crystal ingestion has been performed in the NASA Propulsion Systems Laboratory (PSL)

- The Honeywell Uncertified Research Engine (HURE), a research version of a turbofan engine that never entered production, was tested in the NASA Propulsion System Laboratory (PSL), an altitude test facility at the NASA Glenn Research Center. 
Historical engine icing events and HURE engine test points from PSL Testing with confirmed ice accretion

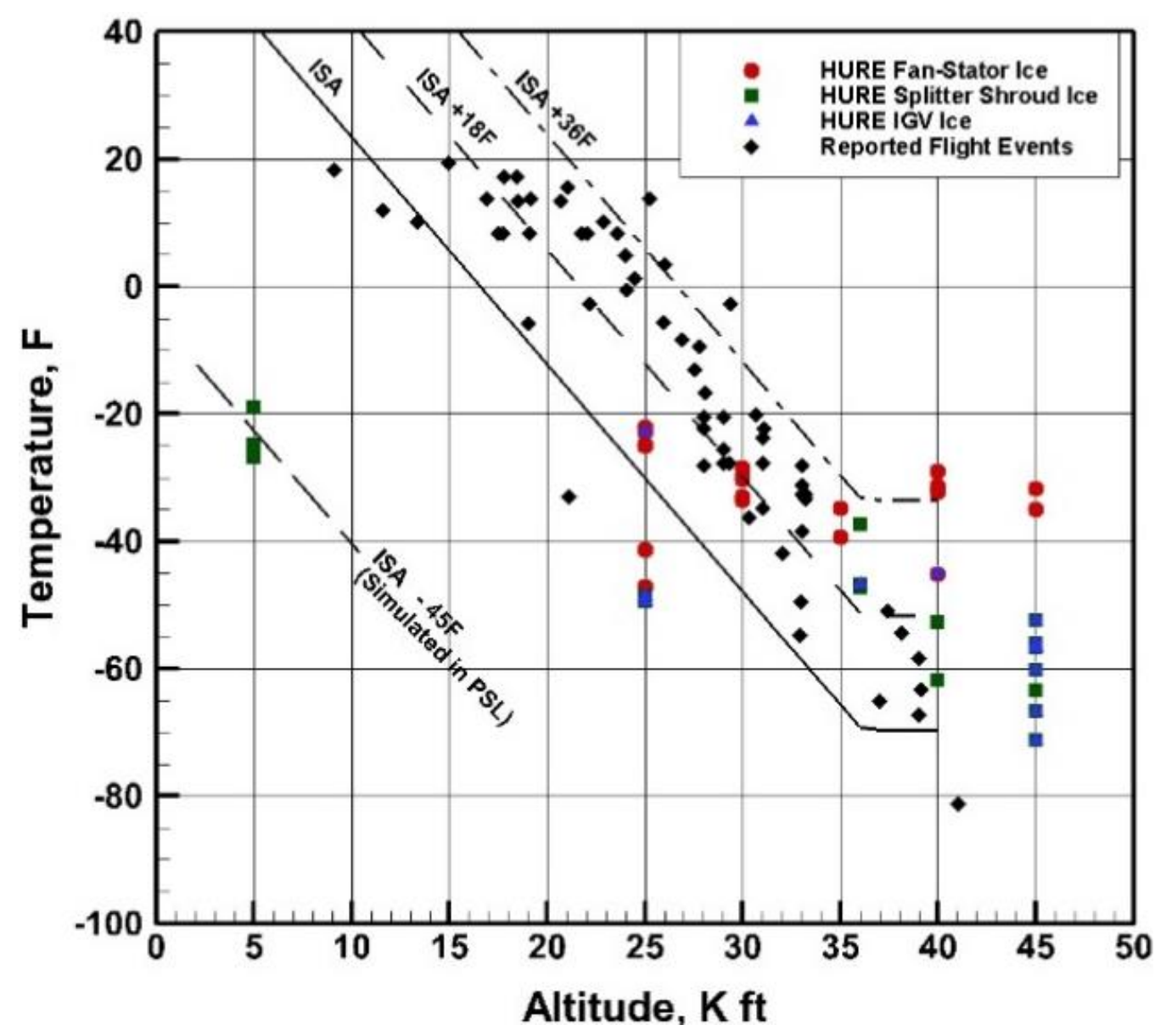

Ref.: Mason, J. G., Chow, P., Fuleki, D. M., "Understanding Ice Crystal Accretion and Shedding Phenomenon in Jet Engines Using a Rig Test," GT2010-22550.

Note that the HURE engine was never in production, and has not experienced in-flight events that have been attributed to ice crystal ingestion. It was tested in PSL as part of NASA engine icing research. 


\section{HURE Engine Testing in PSL at Simulated Altitude} with Ice Crystal Ingestion.

Spray bars

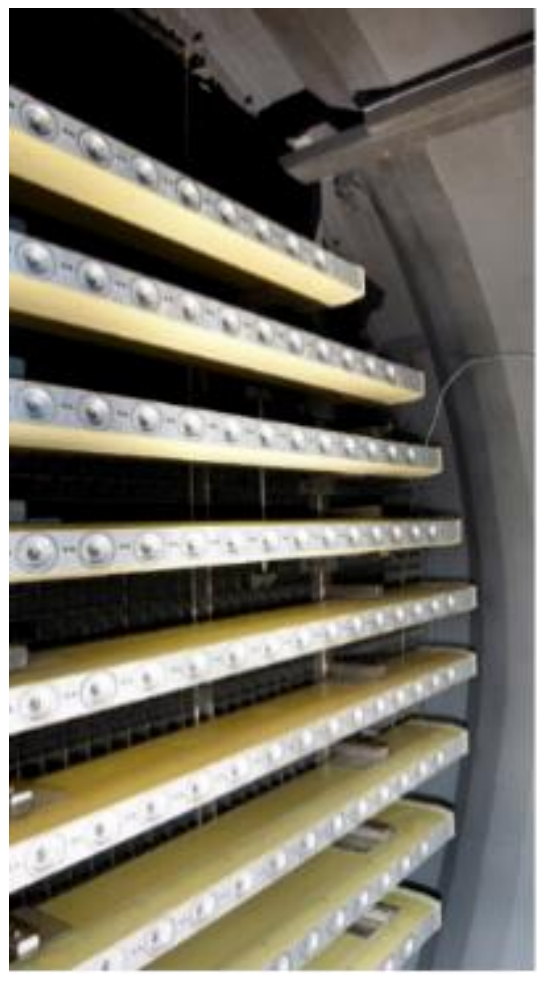

Direct connect duct

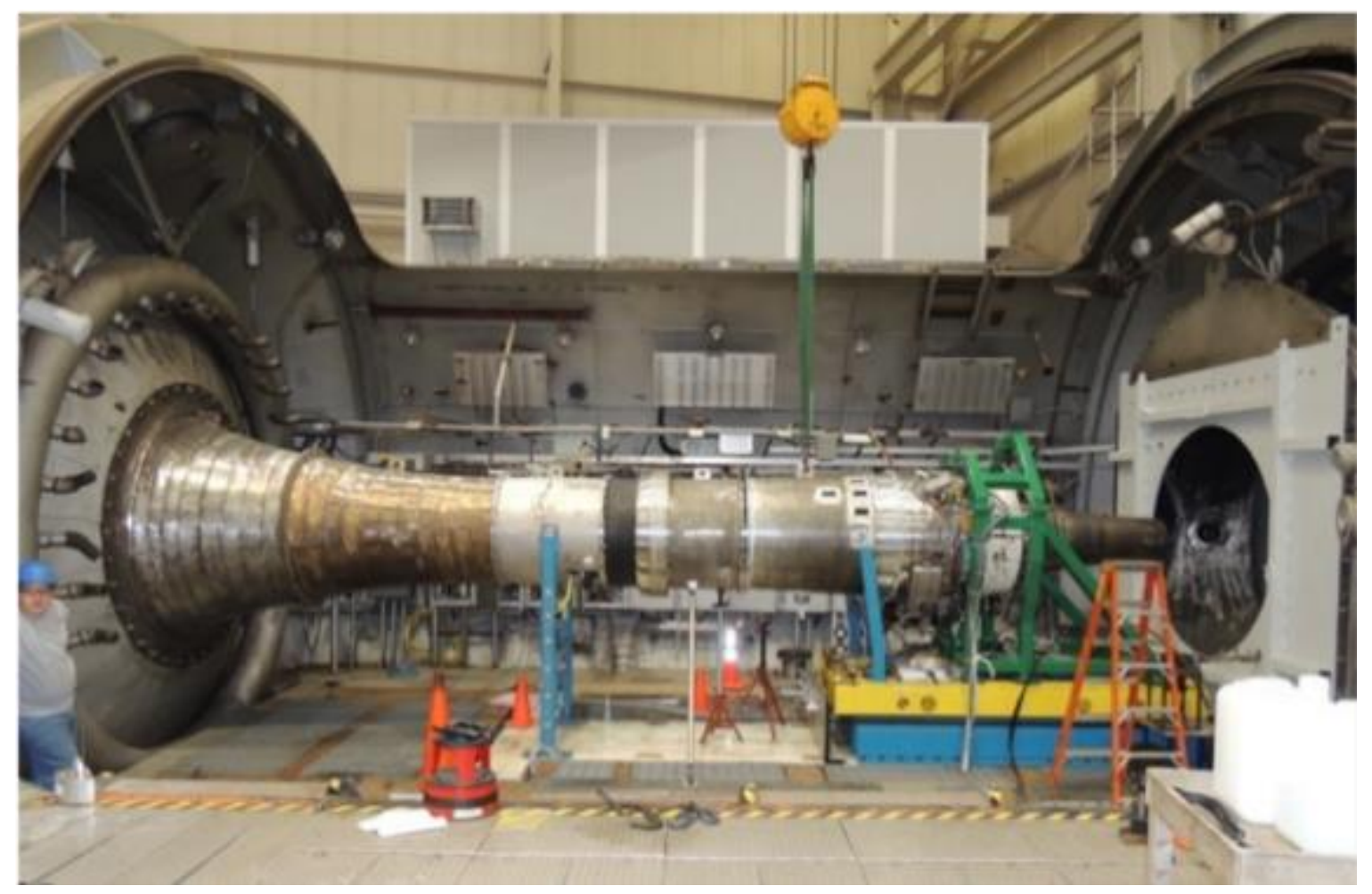

The PSL is equipped with water spray bars capable of producing an ice cloud consisting of ice particles, having a controlled particle diameter and concentration in the air flow. 


\section{Computational Process}

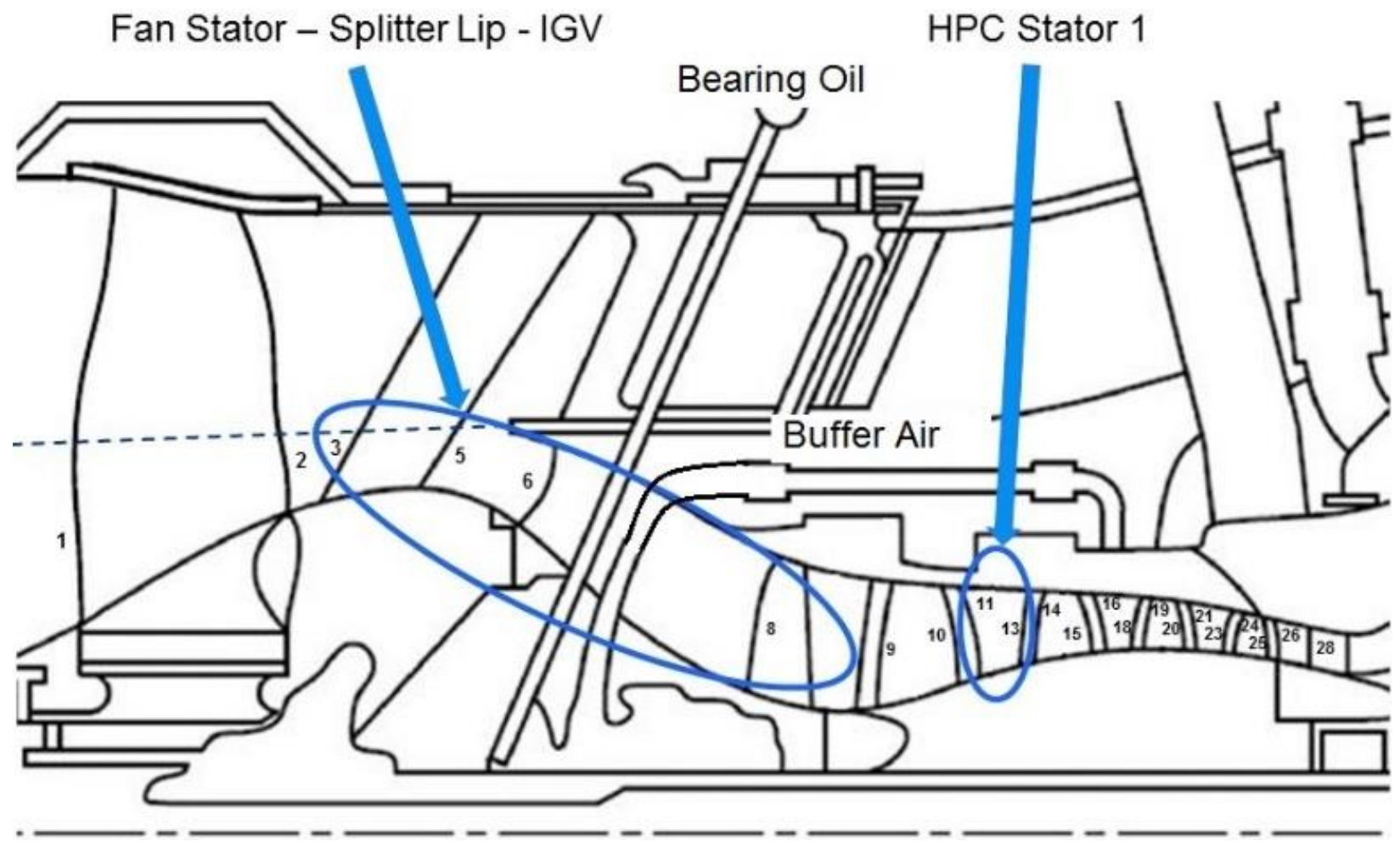

- Honeywell Uncertified Research Engine (Courtesy Honeywell Engines).

- Areas where ice accretion was induced to occur through prediction with COMDES-MELT.

- The prediction for ice accretion risk assumed adiabatic flow path walls. 


\section{Computational process for the test data analysis of the HURE} turbofan engine

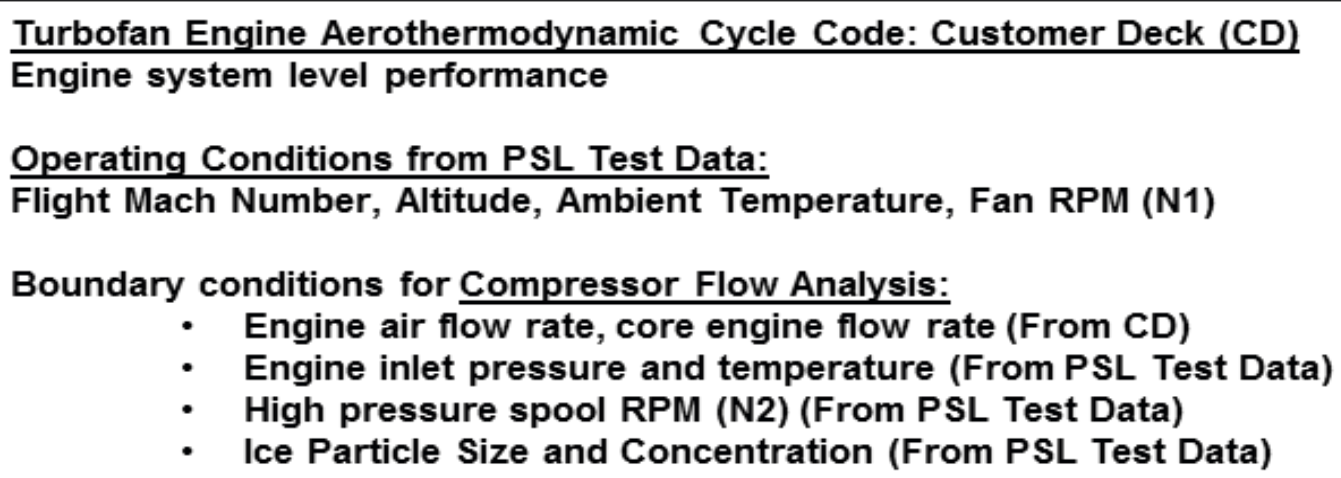

Turbofan Engine Aerothermodynamic Cycle Code: Customer Deck (CD) Engine system level performance

Operating Conditions from PSL Test Data:

Flight Mach Number, Altitude, Ambient Temperature, Fan RPM (N1)

Boundary conditions for Compressor Flow Analysis:

- Engine air flow rate, core engine flow rate (From CD)

- Engine inlet pressure and temperature (From PSL Test Data)

- High pressure spool RPM (N2) (From PSL Test Data)

- Ice Particle Size and Concentration (From PSL Test Data)

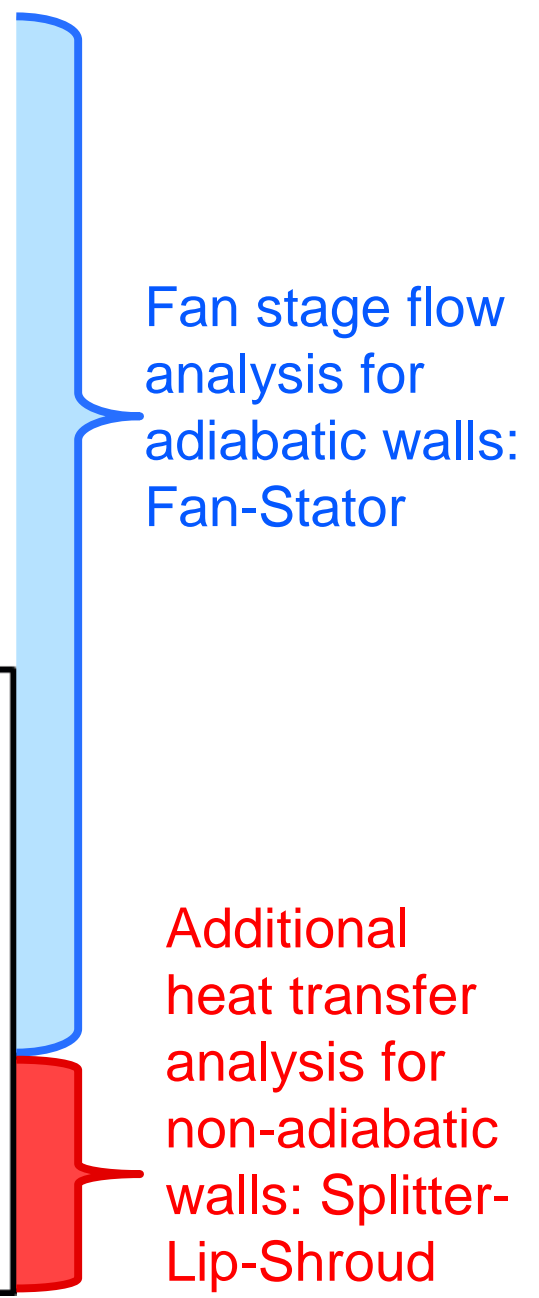




\section{Icing Wedge; defined by the Static Wet Bulb Temperature, IWAR}
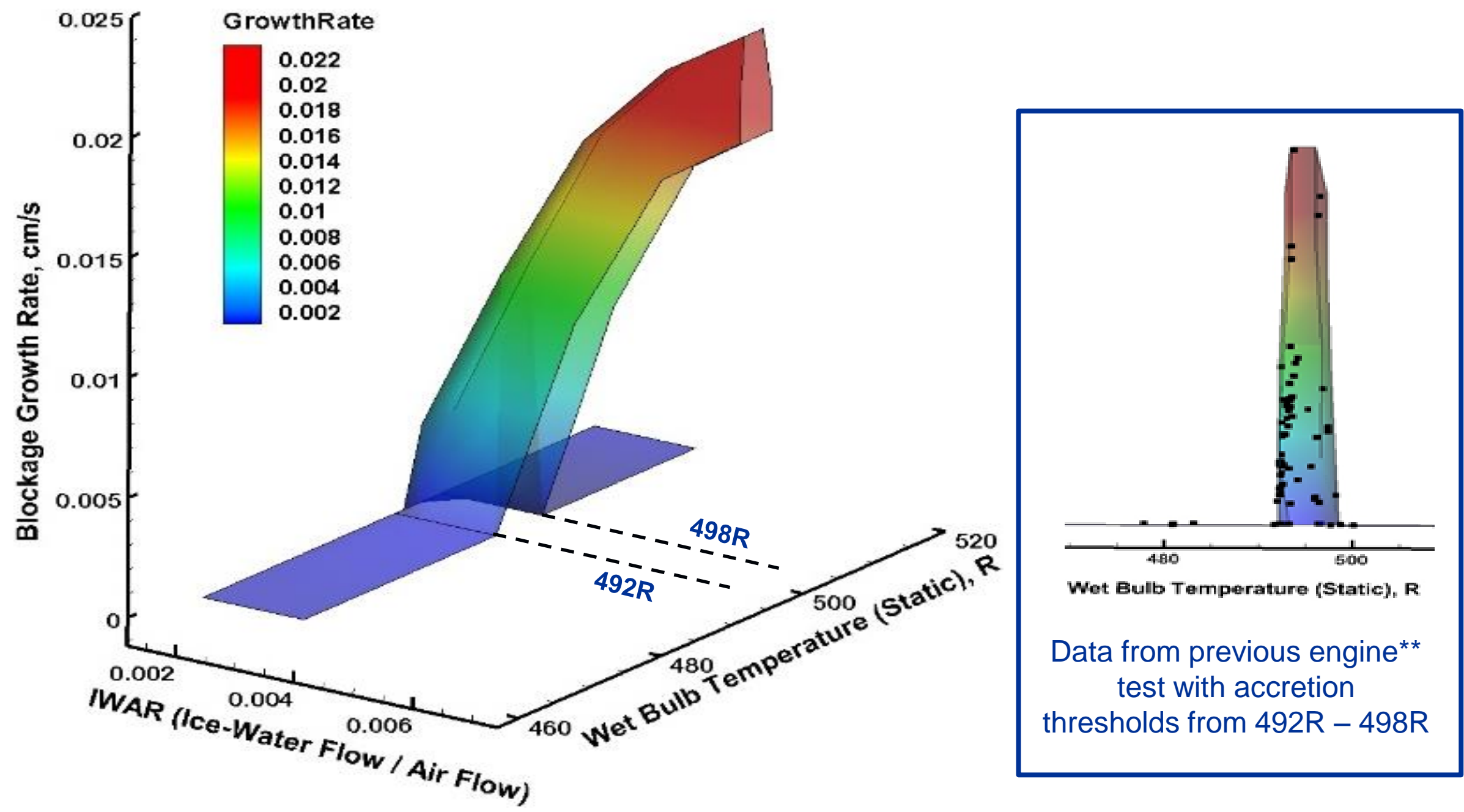

**Reference: Veres, J. P., Jorgenson, P. C. E., Jones, S. M., Nili, S., "Modeling of A Turbofan Engine with Ice Crystal Ingestion in the NASA Propulsion System Laboratory," GT2017-63202. 
Static Wet Bulb Temperature: a function of relative humidity

Distribution of relative and specific humidity through the Fan (Stations 1-5), Splitter-Strut (Stations 6-8) and HPC Axial Compressor Stages (stations 9-28)

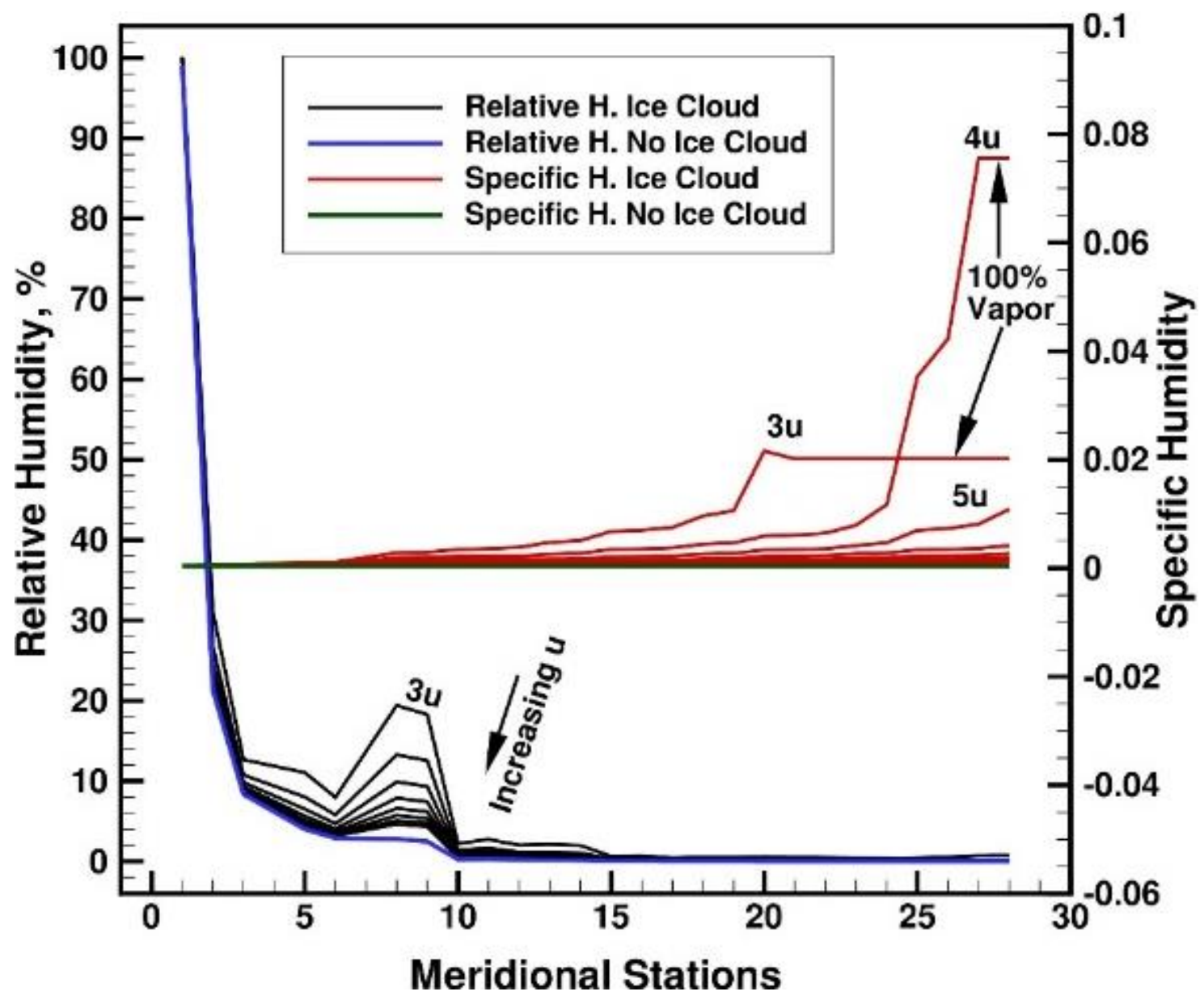




\section{Engine and Compressor Flow Analysis: Fan-Stator}

- During testing, it was observed by video confirmation that ice accreted at the fan-stator at mid-span location, from mid-chord to the trailing edge.

- Real-time flow analysis confirmed that this was in accordance with the icing parameter thresholds of minimum and maximum static wet bulb temperature, and IWAR; as governed by the Icing Wedge, with a non-zero melt ratio.

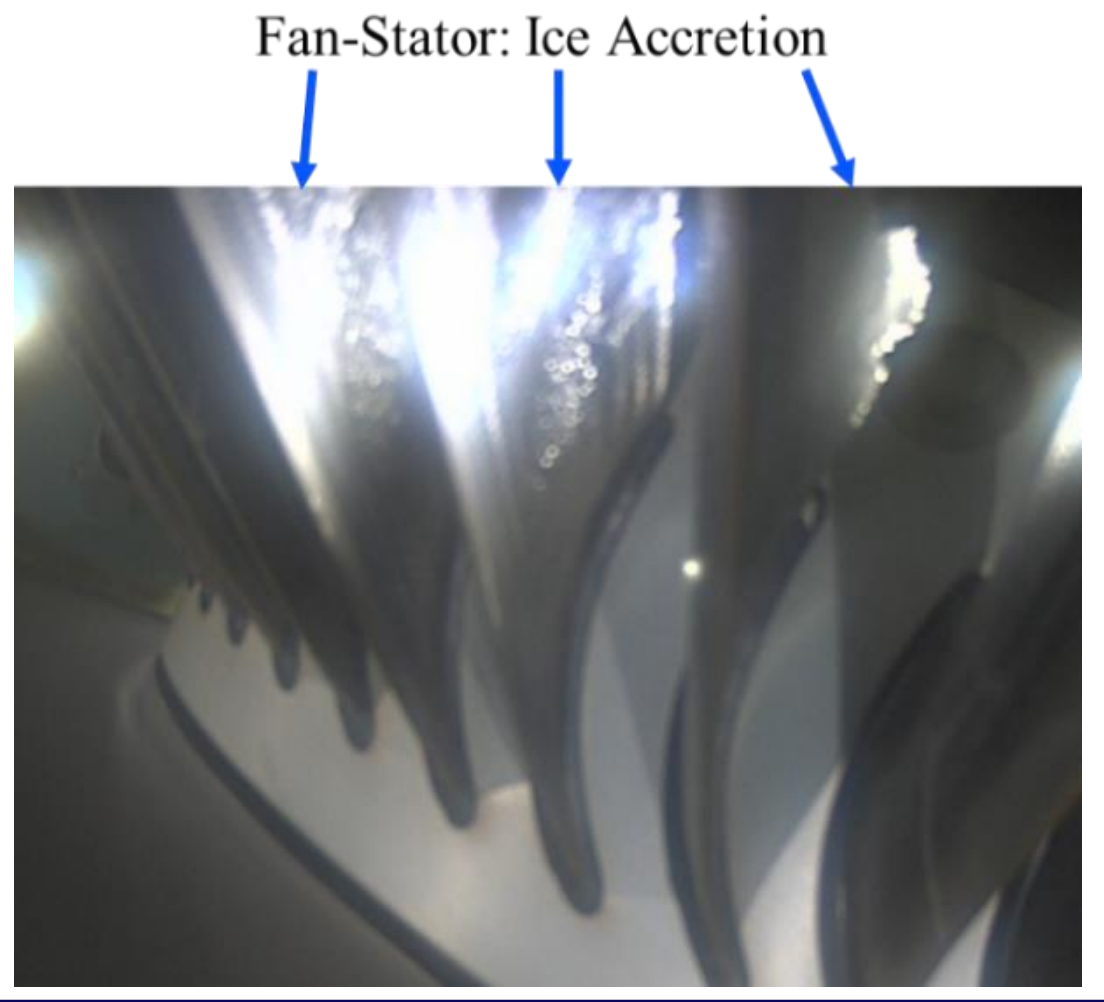




\section{Engine and Compressor Flow Analysis: Fan-Stator}

Fan Stage - Two flow models with the COMDES-MELT code to determine the static wet bulb temperature and melt ratio at the fan-stator:

Full fan model (rotor and stator) at the RMS radius.

- Fan-core model (rotor and stator, but with the outer flow path wall indicated by the notional streamline) at the RMS radius.

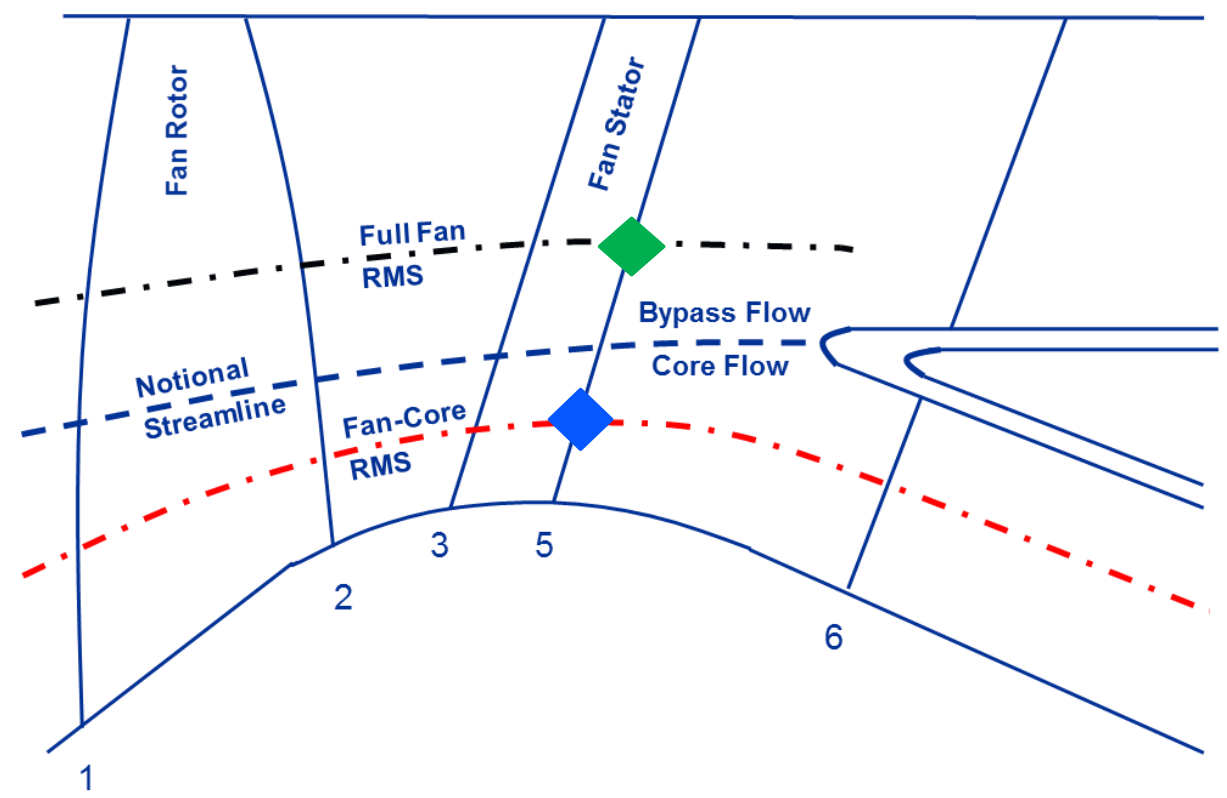

The numbers $1-5$ are meridional stations in the flow model 


\section{Engine and Compressor Flow Analysis: Fan-Stator}

Typical Icing Data Point

Video camera view showing ice accretion on the fan stator

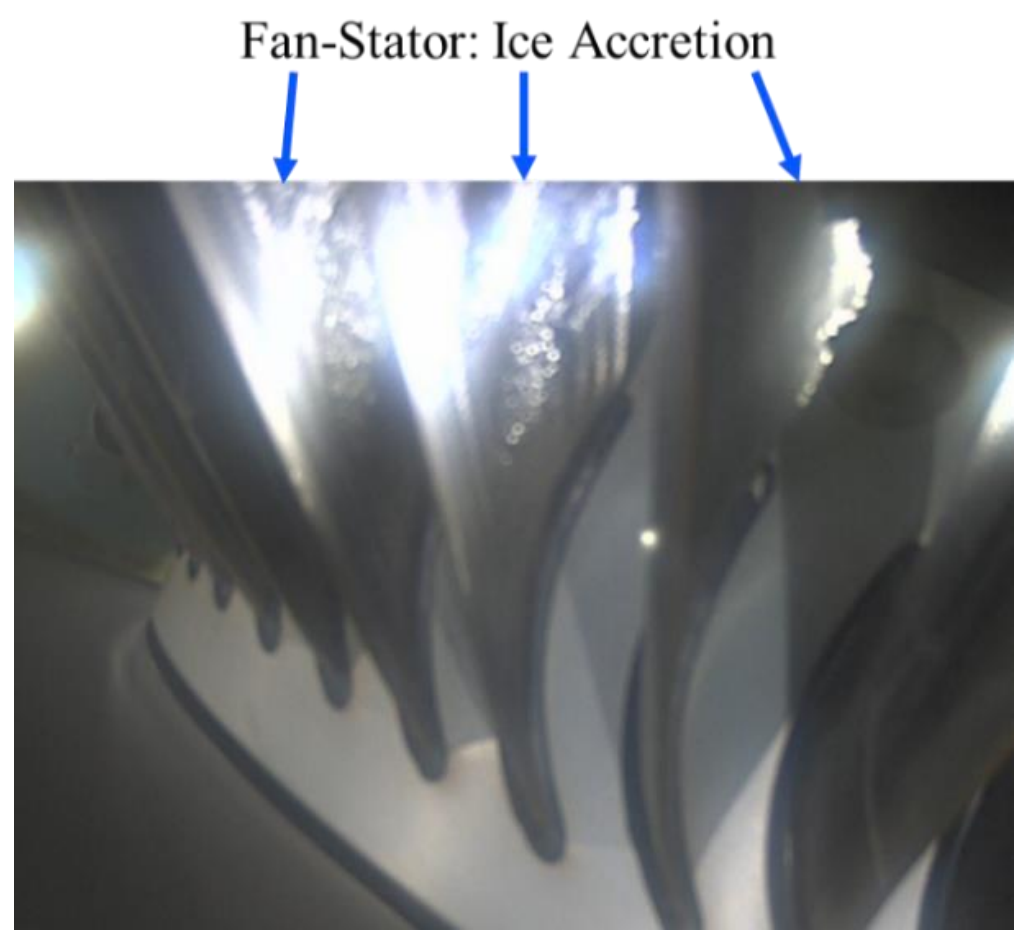

Flow Analysis of the full fan, and the fan-core, showing the static wet bulb temperature was within the Icing Wedge thresholds in the fanstator (stations 3 - 5) between the two RMS radii

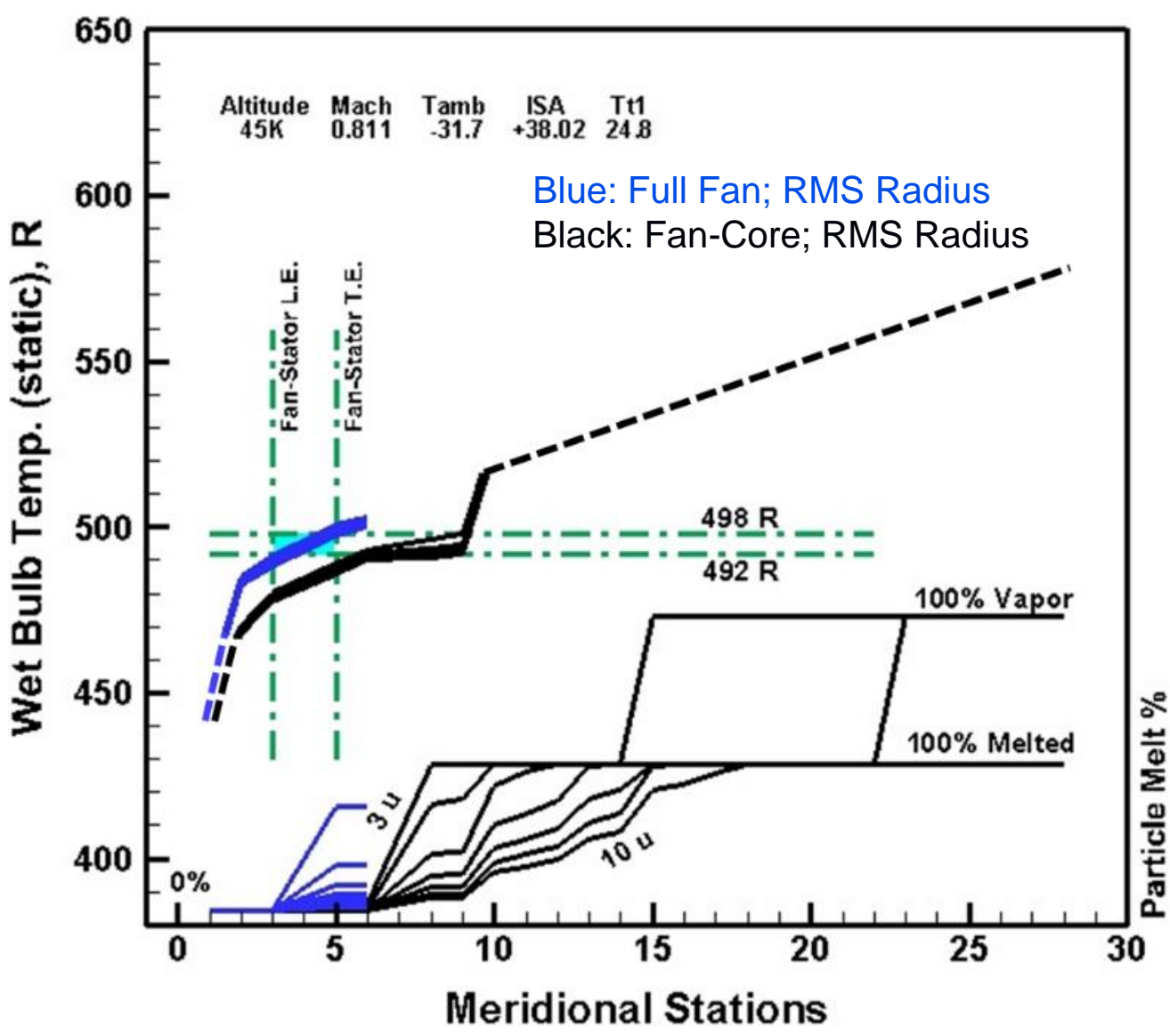




\section{Engine and Compressor Flow Analysis: Fan-Stator}

Comparison of the Icing Wedge to the range of static wet bulb temperature at the fan-core stator and full fan-stator root-mean-square radii.

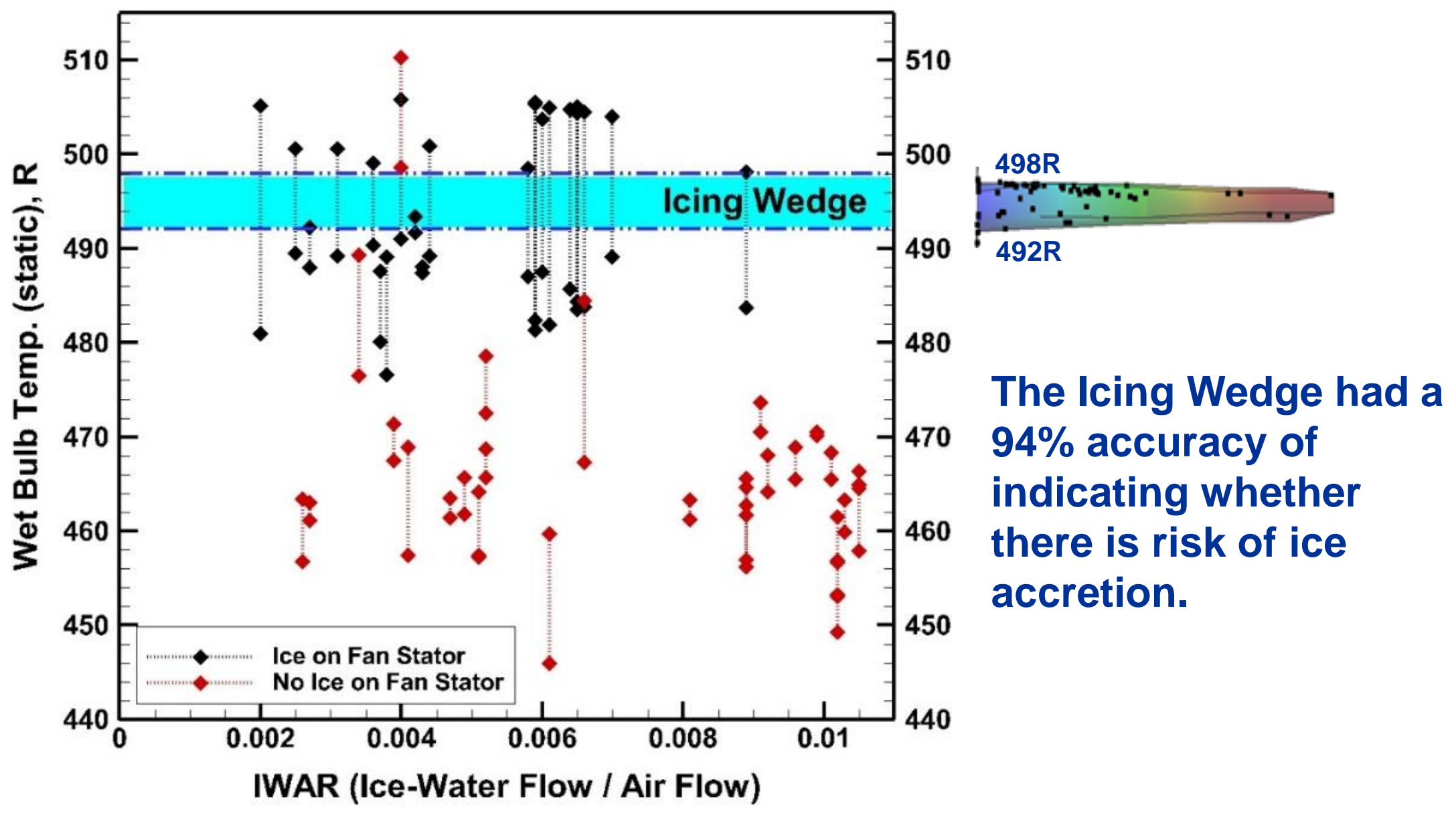


Engine and Compressor Flow Analysis;

with Heat Transfer Model: Splitter-Lip-Shroud Region

Ice accretion near the splitter-lip-shroud occurred at static wet bulb temperatures on the order of $24 \mathrm{R}$ lower than the Icing Wedge minimum temperature threshold. This was due to the possible non-adiabatic process in the splitter-lip-shroud region. To estimate the wall temperature, the analysis utilizes a heat transfer model to calculate heat flux to the ice particles.

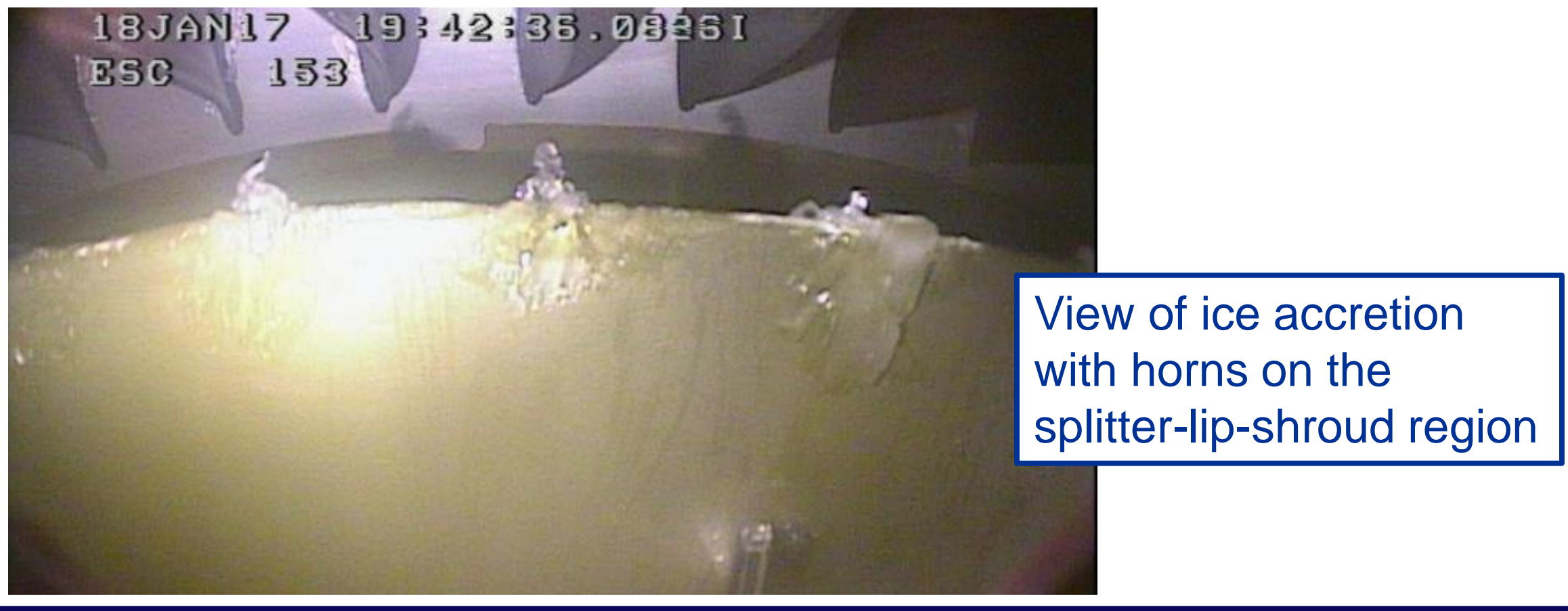




\section{Splitter-Lip-Shroud Region; Non-Adiabatic Wall}

Real-Time Predictions: during PSL Test, reducing the Icing Wedge thresholds by $24 \mathrm{R}$

Post-Test Analysis: Order-of-Magnitude Estimate of Wall Temperature ( $\left.T_{\text {wallcore }}\right)$

$$
\begin{aligned}
& Q=S H C * m *\left(T_{\text {particle }}-T_{\text {wall core }}\right) \\
& T_{\text {wall plenum }}=Q * \frac{\text { Thickness }}{(A * k)}+T_{\text {wall core }} \\
& h_{\text {wall plenum }}=\frac{Q}{A *\left(T_{\text {wall plenum }}-T_{\text {air plenum }}\right)}
\end{aligned}
$$

$T_{\text {wallcore }}=\left(A / 144 * h_{\text {wallplenum }} * k * T_{\text {airplenum }}+m * 3600 * S H C *\left(k-h_{\text {wallplenum }} *\right.\right.$ Thick $\left./ 12) * T_{\text {particle }}\right) /\left(A / 144 *\right.$ hwallplenum $* k+m * 3600 * S H C *\left(k-h_{\text {wallplenum }} *\right.$ Thick /12))

Note: The $\boldsymbol{h}_{\text {wall plenum }}$ was first derived empirically using two test data points with visually confirmed hard ice on the splitter-lip and shroud, which did not shed. 


\section{Splitter-Lip-Shroud Region; Non-Adiabatic Wall}

Wall temperature comparison during ice accretion;

$\underline{\text { Measured LF11 data; and Calculated }} T_{\text {wallcore }}$ of splitter-lip-shroud

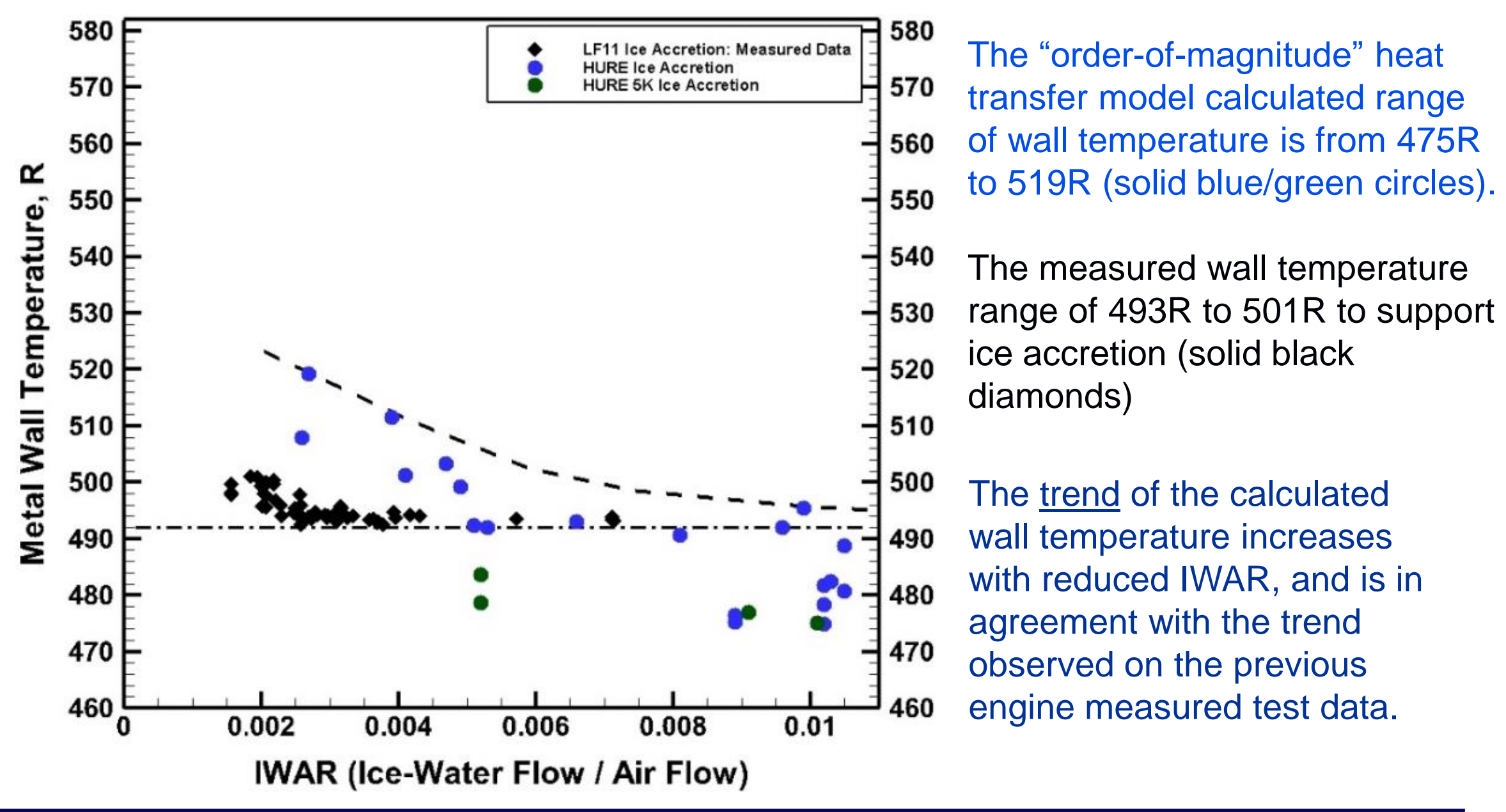


Splitter-Lip-Shroud Region; Non-Adiabatic Wall

\section{Accretion WITH HORNS (153)}
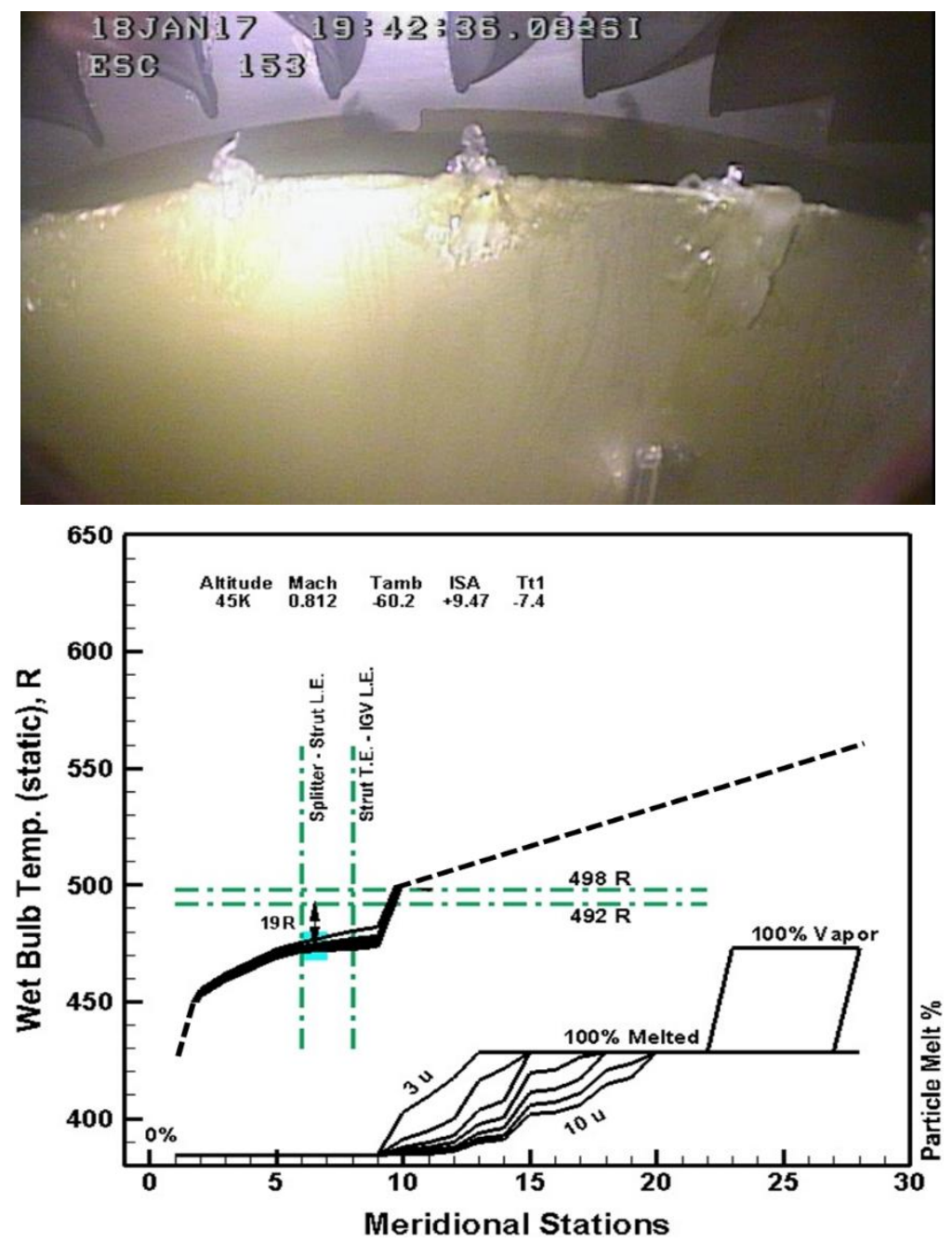

Twbs < 19R below Icing Wedge

Twallcore $=495 \mathrm{R}$

\section{Accretion NO HORNS (156)}
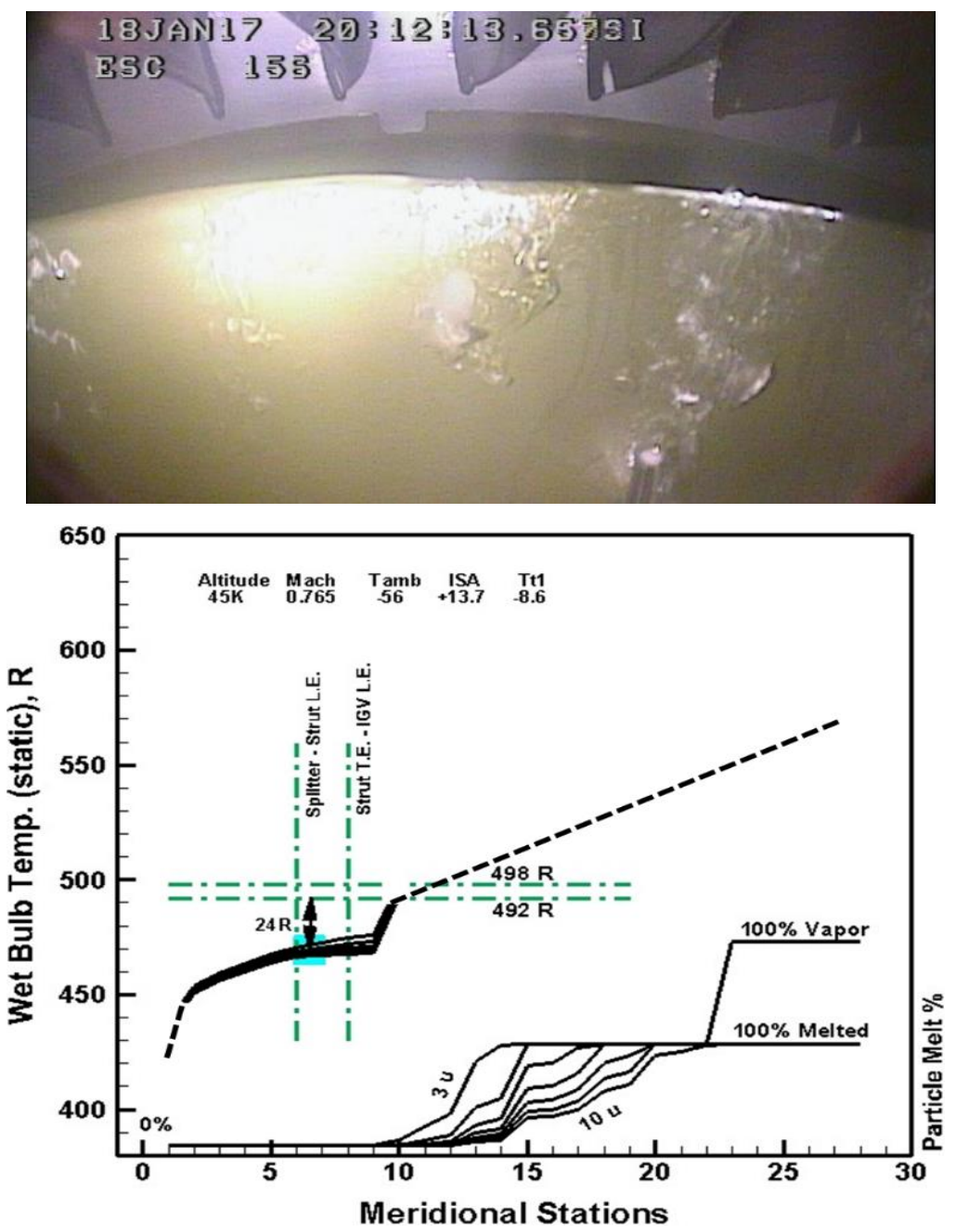

Twbs $<24 \mathrm{R}$ below Icing Wedge

Twallcore $=492 \mathrm{R}$ 
Engine and Compressor Flow Analysis: Inlet Guide Vane

Ice accretion on the variable IGV was observed only at very high values of ice-water flow rate to air flow rate (IWAR). This may be due to the "hidden core" feature of this engine, which may effectively minimize the amount of ice particles entering the core.

The measured vane metal temperature during data points with ice accretion was $\sim 492 \mathrm{R}$, with little or no shedding, or slow shedding cycles. At slightly higher measured vane temperatures there was ice collection with rapid build-shed cycles.

the Icing Wedge thresholds not applicable as an indicator of accretion risk at the IGV, possibly due to the presence of the upstream nonadiabatic splitter-lip-shroud walls, that provide a source of liquid water to the IGV. 
Engine and Compressor Flow Analysis: Inlet Guide Vane Measured IGV metal temperatures versus IWAR; video confirmation

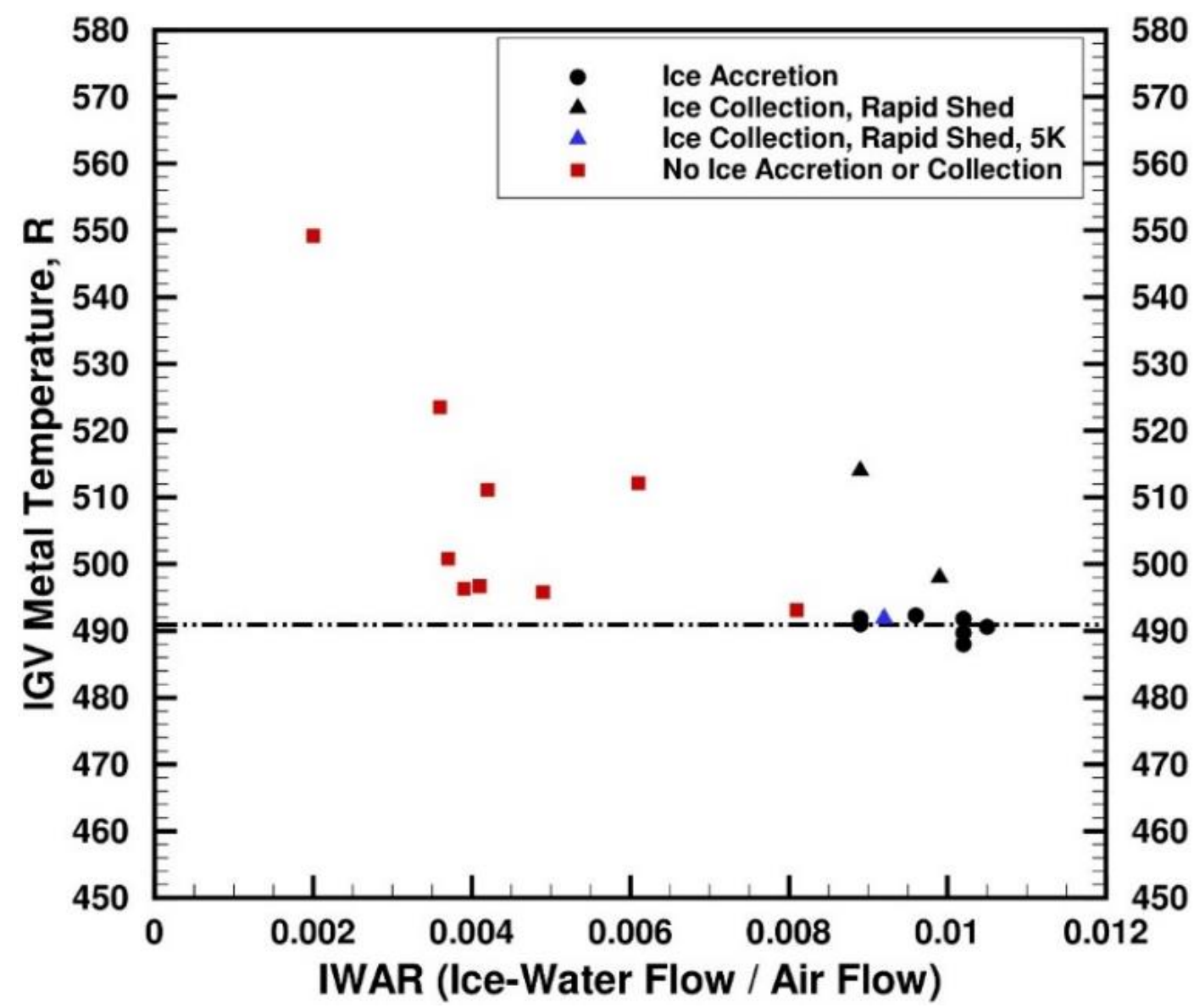

Accretion on the IGV appeared to be a function of IWAR for all operating points.

For all test points the minimum limit where ice accretion occurred had IWAR values above 0.008

The data with red symbols indicate no accretion or collection

The data with black and blue symbols indicate ice accretion or collection.

The Icing Wedge temperature thresholds were not applicable as an indicator of icing risk due to the source of liquid water from the upstream splitter-lip-shroud region. 


\section{Engine and Compressor Flow Analysis: Inlet Guide Vane}

Ice Accretion on the IGV at IWC $=4.1$; and IWAR $=0.011$

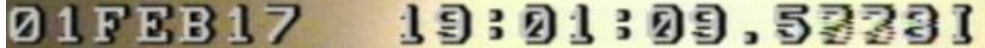 ESC 2334}

Twallcore, Measured $=491 \mathrm{R}$ after 60 seconds of ice cloud initiation

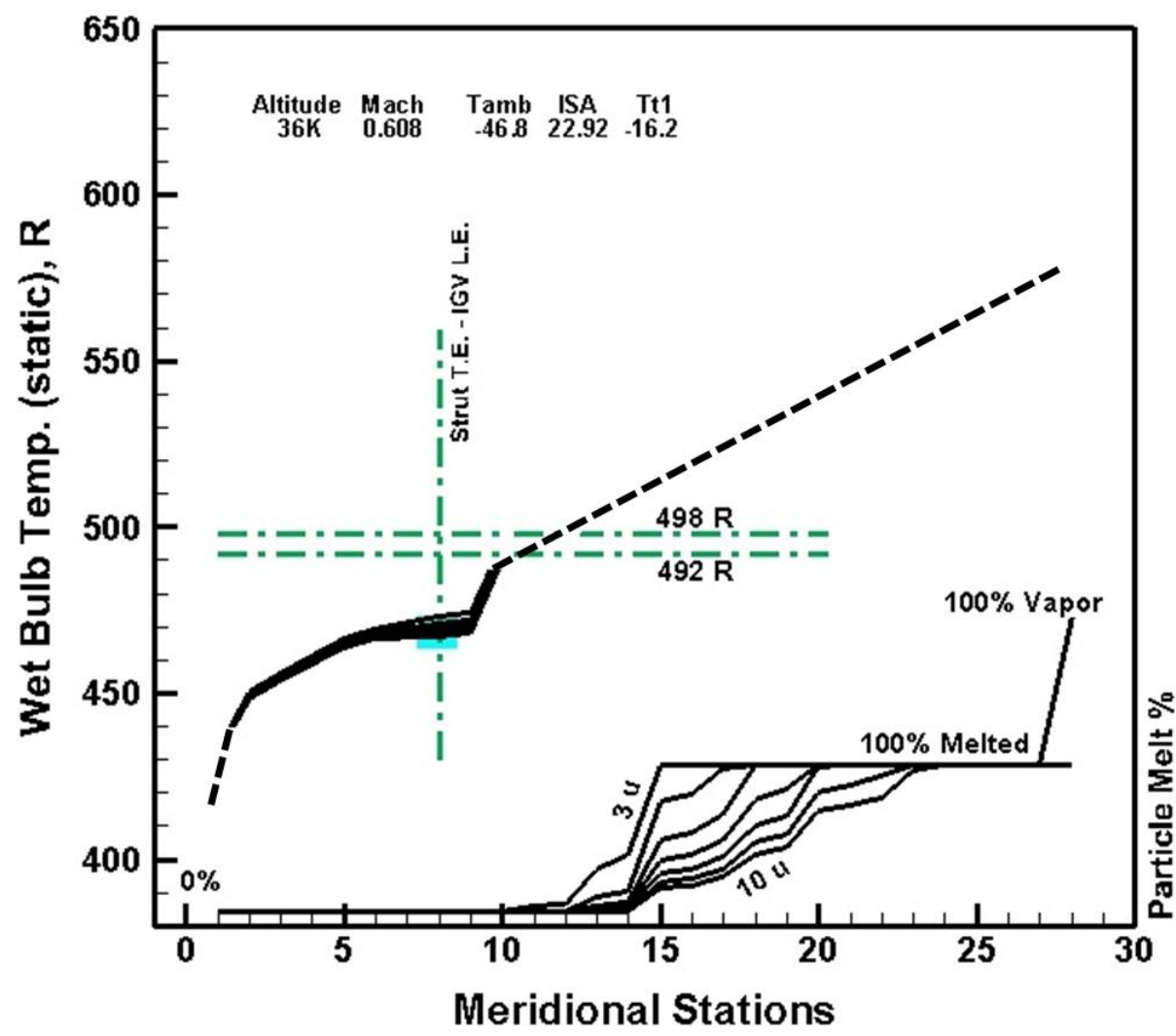

Twbs $<22 \mathrm{R}$ below Icing Wedge threshold at meridional station 8 (IGV leading edge) 


\section{Conclusions}

- The Honeywell Uncertified Research Engine has been tested in the Propulsion System Laboratory at NASA Glenn Research Center with ice crystal cloud ingestion.

- A computational process utilizing the mean-line (COMDES-MELT) aerodynamic compressor flow analysis code along with the Honeywell customer deck were utilized for the post-test analysis.

- The HURE engine testing indicates that ice accretion occurred differently in the fan-stator, than it does near the splitter-lip and shroud region, as well as on the compressor inlet guide vane.

- Ice accretion on the adiabatic fan-stator vanes occurs within the range of wet bulb temperature thresholds of the Icing Wedge (492R - 498R), with 94\% accuracy. The mean-line flow analytical capability with the Icing Wedge thresholds is an effective tool for estimating icing risk in adiabatic regions. 


\section{Conclusions, continued}

- The splitter-lip-shroud region were non-adiabatic, and the target Twbs for prediction of ice accretion during testing was reduced nominally by $24 \mathrm{R}$ from the Icing Wedge minimum threshold temperature.

- A simple heat transfer model was developed for an order-of-magnitude calculation of the wall temperature in the splitter-shroud region. The calculated wall temperature that supports ice accretion had a range of 475R-519R, which spanned the measured values from a previous engine of between 493R - 501R.

- The ice accretion on the variable IGV appeared to be a strong function of the IWAR, and occurred at measured metal temperatures near 492R.

- Non-adiabatic compressor flow path walls require a fully coupled multidisciplinary analysis of the conjugate heat transfer through the walls, the air flow, as well as the thermodynamic state of the ice particle, in order to determine the static wet bulb temperature distribution in the flow field. 